\title{
Long-acting reversible contraceptive use in the post-abortion period among women seeking abortion in mainland China: intentions and barriers
}

\author{
Zhongchen Luo ${ }^{1}$, Lingling Gao ${ }^{2^{*}}$, Ronald Anguzu ${ }^{3}$ and Juanjuan Zhao ${ }^{2}$
}

\begin{abstract}
Background: This study aimed to describe the intentions of and barriers to the use of long-acting reversible contraceptives (LARCS) in the post-abortion period among women seeking abortion in mainland China.

Methods: A cross-sectional study was conducted from July 2015 to December 2015 using a waiting room questionnaire. A total of 381 women seeking abortions were recruited at a public hospital abortion clinic. The outcome variable was an 'intention-to-use' LARCs in the immediate post-abortion period. Chi-square tests were used to assess associations between categorical variables. Statistically significant variables $(p \leq 0.05)$ were then further analyzed by logistic regression.

Results: Among 381 respondents, 42.5\% intended to use LARCs in the immediate post-abortion period; 35.2\% intended to use intra-uterine devices (IUDs); and 13.9\% intended to use implants. Previous use of LARC was a predictor for an intention to use LARCs (odds ratio $[\mathrm{OR}]=2.41 ; 95 \%$ confidence interval $[\mathrm{Cl}]$ : 1.06-5.47). Participants with one or no child had reduced odds for an intention to use LARC (OR $=0.32,95 \% \mathrm{Cl}: 0.15-0.47$ and OR $=0.29$, 95\% Cl: 0.13-0.68, respectively). Women with a higher sex frequency (at least once per week) showed increased odds for LARC use $(\mathrm{OR}=3.34 ; 95 \% \mathrm{Cl}: 1.03-10.78)$ and married women were more likely to use LARC than single women $(\mathrm{OR}=1.57 ; 95 \% \mathrm{Cl}: 1.00-2.47)$. Women who planned to have another baby within two years were more likely not to use LARCs in the immediate post-abortion period $(\mathrm{OR}=0.97 ; 95 \% \mathrm{Cl}: 0.43-2.12)$. Barriers to the use of LARCs were anxiety relating to impaired future fertility (56.2\%), LARCs being harmful to health (45.2\%), irregular bleeding (44.3\%), risk of IUD failure (41.6\%) and lack of awareness with respect to LARCs (36.1\%).

Conclusions: Intention to use LARCs was predicted by marital status, frequency of sexual activity, number of children, planned timing of next pregnancy, and previous LARC use. Impaired future fertility, being harmful to health, irregular bleeding, risk of complications, and lack of awareness with regards to LARCs were the main barriers in their potential use.
\end{abstract}

Keywords: Long acting reversible contraception, Intrauterine devices, Implants, Induced abortion, Intention, Barriers

\footnotetext{
* Correspondence: gaoll@mail.sysu.edu.cn

${ }^{2}$ School of Nursing, Sun Yat-sen University, 74\#, Zhongshan Road II,

Guangzhou 510089, China

Full list of author information is available at the end of the article
}

(c) The Author(s). 2018 Open Access This article is distributed under the terms of the Creative Commons Attribution 4.0 International License (http://creativecommons.org/licenses/by/4.0/), which permits unrestricted use, distribution, and reproduction in any medium, provided you give appropriate credit to the original author(s) and the source, provide a link to the Creative Commons license, and indicate if changes were made. The Creative Commons Public Domain Dedication waiver (http://creativecommons.org/publicdomain/zero/1.0/) applies to the data made available in this article, unless otherwise stated. 


\section{Plain English summary}

Long-acting reversible contraceptives (LARCs) are the most cost-effective contraceptives for the prevention of unintended pregnancies, and the use of these medications during the post-abortion period reduces the rate of repeat abortions. However, the willingness of women to use LARCs during the post-abortion period remains uncertain; intentions and potential barriers to their use therefore require further investigation. This study explores the intentions and barriers to the use of LARC in the post-abortion period among pregnant women seeking abortion in mainland China.

Information was collected using a field questionnaire survey by convenience sampling methods. The survey contained 18 questions including socio-demographic information, sexual and reproductive health history, awareness, experience, intention, and barriers to use for each type of LARC in the immediate post-abortion period.

Of the 381 women seeking abortion with unintended pregnancy, approximately $42.5 \%$ were interested in using LARCs during the post-abortion period. $35.2 \%$ intended to use intra-uterine device (IUDs), while nearly $13.9 \%$ of the women intended to use the implant method during the post-abortion period, which suggested that this cohort of women preferred IUDs over implants. Intention to use LARCs was predicted by marital status, frequency of sexual activity, number of children, planned timing of the next pregnancy, and previous LARC use. Impaired future fertility, being harmful to health, irregular bleeding, risk of complications, and lack of awareness were the main barriers to the use of LARC. In order to increase access to LARCs in order to reduce unintended pregnancies in women, education and communication should focus on alleviating barriers to the use of LARCs.

\section{Background}

Unintended pregnancy is an important public health challenge cross the world, as well as in mainland China. Unintended pregnancy has negative effects on the health of the mother and baby, leading to a sizeable, and potentially avoidable, cost burden [1]. According to the Chinese 'health and family planning statistics annual publication' (2014), unintended pregnancy results in 6.62 million abortions in mainland China [2]. Moreover, the rate of repeat induced abortions due to unintended pregnancies is also high in mainland China, with nearly half of the women seeking abortion having had at least one previous induced abortion [3]. Unintended pregnancy usually occurs due to contraceptive issues including emergency contraception failure (33.1\%), incorrect use of contraception or a lack of condoms (28.6\%) and use of the rhythm method (21.9\%). Short-term family planning methods are less effective, and have a higher risk of contraceptive failure [4].

Long-acting reversible contraceptives (LARCs) are a type of contraceptive that is easily reversed and do not rely on the user to maintain efficacy for at least three years. Typical examples include intra-uterine devices (IUDs) and implants [5]. These are user-independent and exhibit higher compliance than short-acting methods [6]. Almost all women of reproductive-age who use LARCs can return to a fertile state, as the effects are reversible [5]. The mean time until return to fertility following the use of implants or IUDs is within days of cessation; faster than all progestogen-only oral contraceptives [5]. Trussell and Hassan et al. conducted a study to estimate the relative costs of short-acting reversible methods and LARC methods, and reported that LARCs were more cost-effective than short-acting reversible methods such as oral contraceptives, the ring, the patch, or injections over a three-year period [7]. The American College of Obstetricians recommends LARCs as an effective method with which to reduce the risk of unintended pregnancy and abortion [8].

Previous evidence has also shown that the use of LARCs during the post-abortion period reduces repeat abortion rates $[9,10]$. However, LARC methods have been under-utilized during the immediate post-abortion period in mainland China $[11,12]$. To provide a wider choice of more effective methods, and to encourage the continuation of this method, it is important to understand the intentions and barriers to LARC use in women seeking abortion, so that effective counseling practices and promotional policies can be implemented. However, little is known about the intentions and barriers to LARC use in Chinese women seeking abortion. Thus, the present study explored the intentions for LARC use and the factors associated with contraceptive choices among women with unintended pregnancy and seeking abortion in mainland China. Barriers to LARC use in the immediate post-abortion period were also identified.

\section{Methods \\ Study design and setting}

A cross-sectional study was carried out between July and December 2015 in Guangzhou, a sub-provincial city located in Southeastern China. Guangzhou is the capital of the Guangdong Province, and has a population of approximately 16 million [13]. In Guangzhou, the sex ratio is 109.5 male for every 100 female; $68.6 \%$ of women in this region are of reproductive age (15-50 years old) [14]. The total number of health care institutions in Guangzhou is approximately 3749, including 165 hospitals and 16 maternity and child-care centers,. These institutions provide very similar family planning services [15] which are guided by the Post-abortion Care Consortium in May 2002 [16]. One hospital was randomly 
selected for the present study on the basis that it would provide a sufficient sample size.

The study hospital was A-level, has over 3000 beds and provides leading services for post-abortion care in mainland China. The eligible criteria for inclusion in the study were women seeking artificial abortion due to an unintended pregnancy and not having a diagnosed cognitive impairment. Participants received no incentives for participation in this study. Sample size was calculated using the modified Kish-Leslie formula [17].; this calculation told us that we required a sample of 363 women, based on $95 \%$ confidence intervals, $5 \%$ precision and the $38.2 \%$ prevalence of induced abortion in Guangzhou [18].

\section{Data collection}

Ethical approval was obtained from the study hospital. A trained research assistant (RA), who was a masters student majoring in Nursing, was responsible for collecting data. All eligible subjects who were waiting for their appointments at the abortion clinic of the study hospital were invited to participate in the study. The RA explained details of the purpose and procedure of the study to the women. All women who provided informed written consent were asked to fill in questionnaires in an interview room. The RA remained in the vicinity to answer questions and personally collect the returned questionnaires. A total of 399 women were approached, of whom 381 completed the questionnaires.

\section{Measures}

The immediate post-abortion period was defined as the period of time after undergoing medical or surgical abortion, but before resuming intercourse. LARC referred to the use of either implants or IUD contraceptives.

An 18-item questionnaire was used to collect data. Firstly, the definition of "intention to use a LARC" was described as "intending to use either IUDs or implants in the immediate post-abortion period". Subsequently, women were asked whether they intended to use a LARC (Yes or No). Typical questions were "Would you like to use an intra-uterine device for contraception in the immediate post-abortion period?" and "Would you like to use an implant for contraception in the immediate post-abortion period?". In addition, one question investigated personal barriers to the use of LARC. Women were asked to select as many factors as possible from a list of 20 that they perceived as barriers to their use of a LARC. In addition, 5 questions were included which pertained to socio-demographic characteristics including age, marital status, educational level, monthly income and occupation. Six questions referred to sexual and reproductive health history, and subjects were asked questions relating to intercourse frequency, contraceptive use, previous abortions, time from the latest abortion until present, number of children, and expected timing of the next pregnancy. Four questions also referred to awareness and experience regarding the use of any type of LARC.

The 18-item survey questionnaire was based on a comprehensive review of the literature relating to LARCs [19-25]. After the questionnaire was developed, it was reviewed for content validity by four obstetricians and five midwives. These experts provided written feedback on the clarity and relevance of the questionnaire but were not requested to provide a quantitative rating for each item. No item was revised. Before the investigation, the questionnaire was piloted with 10 women seeking abortion in this hospital. All women could understand and complete the questionnaire easily, so no changes were required. The 4-week test-retest correlation for the questionnaire was 0.93 .

\section{Statistical analyses}

The Statistical Package for Social Sciences (SPSS) v20.0 was used for all data entry and analyses. Descriptive statistics summarized the socio-demographic characteristics of the participants, as well as sexual and reproductive health histories, awareness, experience and intention to use LARCs. Differences in the rate of the women's intention to use LARCs among groups with different socio-demographic and reproductive characteristics were computed using the chi-square test. Variables identified as being significant $(p<0.05)$ in these initial tests were then entered into a logistic regression model to determine predictors of the women's intention to use a LARC in the post-abortion period.

\section{Results}

\section{Socio-demographic characteristics}

Table 1 presents the demographic information of our participants. Almost all women (95.5\%) were of Han ancestry with a mean age of $26.9 \pm 5.7$ years. More than half of the participants $(55.6 \%)$ had at least a junior college education. The majority (85.0\%) were employed and approximately half $(50.4 \%)$ were single, had personal monthly incomes over 4000 RMB (60.9\%), and had intercourse at least once a week (61.9\%). Nearly half of the participants $(45.1 \%)$ had a previous induced abortion, about one-third (28.3\%) had a one-year interval from the latest abortion until present, $44.6 \%$ had at least one child, and $47.5 \%$ of the participants did not want any further children, at least for the next two years.

\section{Awareness, experience and intention to use a LARC}

The majority of participants (93.4\%) had previous contraceptive experiences. Although the majority of women $(88.7 \%)$ were aware of LARCs, few $(8.4 \%)$ had 
Table 1 Socio-demographic and reproductive characteristics of participants $(n=381)$

\begin{tabular}{|c|c|}
\hline Variable & Frequency $f(\%)$ \\
\hline \multicolumn{2}{|l|}{$\overline{\text { Age }(\text { years) }}{ }^{a}$} \\
\hline $16-19$ & $20(5.2)$ \\
\hline $20-29$ & $254(66.7)$ \\
\hline $30-44$ & $107(28.1)$ \\
\hline \multicolumn{2}{|l|}{ Marital status } \\
\hline Married & $189(49.6)$ \\
\hline Single & $192(50.4)$ \\
\hline \multicolumn{2}{|l|}{ Level of education } \\
\hline Junior high school or below & 79 (20.7) \\
\hline Middle special / senior high school & 90 (23.6) \\
\hline Junior college & $111(29.1)$ \\
\hline College graduate or higher & $101(26.5)$ \\
\hline \multicolumn{2}{|l|}{ Monthly income } \\
\hline$<4000 ¥$ & $149(39.1)$ \\
\hline 4000-7999 ¥ & $196(51.4)$ \\
\hline$\geq 8000 ¥$ & $36(9.5)$ \\
\hline \multicolumn{2}{|l|}{ Occupation } \\
\hline Unemployed & $57(15.0)$ \\
\hline Employed & $324(85.0)$ \\
\hline \multicolumn{2}{|l|}{ Reproductive characteristics } \\
\hline \multicolumn{2}{|l|}{ Frequency of intercourse } \\
\hline At least one time per week & $236(61.9)$ \\
\hline$<4$ times per month & $125(32.8)$ \\
\hline$<1$ time per month & $20(5.2)$ \\
\hline \multicolumn{2}{|l|}{ Have used contraception } \\
\hline No & $25(6.6)$ \\
\hline Yes & $227(93.4)$ \\
\hline \multicolumn{2}{|l|}{ Have previously had an abortion } \\
\hline No & $207(54.8)$ \\
\hline Yes & $172(45.7)$ \\
\hline \multicolumn{2}{|c|}{ Interval between last two abortions ( $n=172$, months) } \\
\hline$<6$ months & $23(13.4)$ \\
\hline 6-11 months & $26(15.1)$ \\
\hline$\geq 12$ months & $123(71.5)$ \\
\hline \multicolumn{2}{|l|}{ Number of children } \\
\hline 0 & $211(55.4)$ \\
\hline 1 & $111(29.1)$ \\
\hline$\geq 2$ & $59(15.5)$ \\
\hline \multicolumn{2}{|l|}{ Expected timing of next pregnancy (years) } \\
\hline$<2$ years & $160(42.0)$ \\
\hline$\geq 2$ years & $118(31.0)$ \\
\hline Do not want more children & $63(16.5)$ \\
\hline Unknown & $40(10.5)$ \\
\hline
\end{tabular}

${ }^{\mathrm{a}}$ Mean $(\mathrm{SD})=26.87(5.70)$ years previous experience using a LARC $(7.8 \%$ had used IUDs and $1.1 \%$ had used implants). Less than half of the women (42.5\%) intended to use a LARC during the post-abortion period, with 35.2 and $13.9 \%$ intending to use IUDs and implants, respectively (Table 2).

\section{Predicting the intention of Chinese women to use a LARC} Women were more likely to intend to use a LARC during the post-abortion period if they were married, had a greater frequency of sexual activity, had more than one child, had not planned pregnancy within 2 years or had previously used a LARC $\left(\chi^{2}=11.89, p<0.01 ; x^{2}=6.63\right.$, $p=0.04 ; \chi^{2}=20.87, p<0.01 ; \chi^{2}=11.83, p<0.01 ; \chi^{2}=$ $7.63, p<0.01$ ) (Table 3).

Variables that had significant correlation with a woman's intention to use a LARC were retained in a subsequent logistic regression model. A best-fit regression model indicated that marital status, intercourse frequency, number of live children, planned timing of next pregnancy and previous LARC use were all significant predictors of a woman's intention to use a LARC during the post-abortion period (Table 4).

\section{Barriers to the use of LARCs during the immediate post- abortion period}

Participants without intention to use a LARC during the post-abortion period $(n=219)$ were asked to report their perceived barriers to the use of LARCs. The barriers among this group varied. The most frequently mentioned

Table 2 Relationship with the use of LARCs during the immediate post-abortion period among Chinese women with unintended pregnancy seeking abortions $(n=381)$

\begin{tabular}{ll}
\hline Item & Frequency $f(\%)$ \\
\hline Are aware of LARC & $43(11.3)$ \\
No & $338(88.7)$ \\
Yes & $338(88.7)$ \\
IUDs & $50(13.9)$ \\
Implants & $50(13.9)$ \\
Implants and IUDs & \\
Previous LARC use & $349(91.6)$ \\
No & $32(8.4)$ \\
Yes & $28(7.8)$ \\
IUDs & $4(1.1)$ \\
Implants & $219(57.5)$ \\
Intended to use LARC in immediate post-abortion period \\
No & $162(42.5)$ \\
Yes & $134(35.2)$ \\
IUDs & $53(13.9)$ \\
Implants & $25(6.6)$ \\
Implants or IUDs & \\
\hline
\end{tabular}


Table 3 Associations between demographic/reproductive factors and an intention to use LARCs within women with unintended pregnancy during the post-abortion period $(n=381)$

\begin{tabular}{|c|c|c|c|c|}
\hline & $\begin{array}{l}\text { Intended to use LARC }(n=162) \\
f(\%)\end{array}$ & $\begin{array}{l}\text { No intended to use LARC }(n=219) \\
f(\%)\end{array}$ & $x^{2}$ & $P$ \\
\hline \multicolumn{3}{|l|}{ Age (years) } & 4.02 & 0.13 \\
\hline $16-19$ & $7(4.3)$ & $13(5.9)$ & & \\
\hline $20-29$ & $101(62.3)$ & $153(69.9)$ & & \\
\hline $30-44$ & $54(33.3)$ & $53(24.2)$ & & \\
\hline \multicolumn{3}{|l|}{ Marital status } & 11.89 & $0.01^{* *}$ \\
\hline Married & $97(59.9)$ & $92(42.0)$ & & \\
\hline Single & $65(40.1)$ & $127(58.0)$ & & \\
\hline \multicolumn{3}{|l|}{ Level of education } & 3.40 & 0.26 \\
\hline Junior high school or below & $41(25.3)$ & $38(17.4)$ & & \\
\hline Middle special/senior high school & $38(23.5)$ & $52(23.7)$ & & \\
\hline Junior college & $42(25.9)$ & $69(31.5)$ & & \\
\hline College graduate or higher & $41(25.3)$ & $60(27.4)$ & & \\
\hline \multicolumn{3}{|l|}{ Personal monthly income (RMB) } & 0.12 & 0.94 \\
\hline$<4000$ & $65(40.1)$ & $84(38.4)$ & & \\
\hline 4000-7999 & $82(50.6)$ & $114(52.1)$ & & \\
\hline$\geq 8000$ & $15(9.3)$ & $21(9.6)$ & & \\
\hline \multicolumn{3}{|l|}{ Occupation } & 1.20 & 0.27 \\
\hline Unemployed & $28(17.3)$ & $29(13.2)$ & & \\
\hline Employed & $134(82.7)$ & $190(86.8)$ & & \\
\hline \multicolumn{5}{|l|}{ Reproductive characteristics } \\
\hline \multicolumn{3}{|l|}{ Frequency of sexual activity } & 6.63 & $0.04^{*}$ \\
\hline At least once a week & $110(67.9)$ & $126(57.5)$ & & \\
\hline$<4$ times per month & $48(29.6)$ & $77(35.2)$ & & \\
\hline$<1$ time per month & $4(2.5)$ & $16(7.3)$ & & \\
\hline \multicolumn{3}{|l|}{ Has used a contraceptive } & 2.31 & 0.13 \\
\hline No & $7(1.3)$ & $18(8.2)$ & & \\
\hline Yes & $155(95.7)$ & $201(91.8)$ & & \\
\hline \multicolumn{3}{|l|}{ Has had an abortion } & 2.68 & 0.10 \\
\hline No & $81(50.0)$ & $128(58.4)$ & & \\
\hline Yes & $81(50.0)$ & $91(41.6)$ & & \\
\hline \multicolumn{3}{|c|}{ Interval between last two abortions ( $n=172$, months) } & 0.89 & 0.64 \\
\hline$<6$ months & $12(12.9)$ & $11(13.9)$ & & \\
\hline $6-11$ months & $12(12.9)$ & $14(17.7)$ & & \\
\hline$\geq 12$ months & $69(74.2)$ & $54(68.4)$ & & \\
\hline \multicolumn{3}{|l|}{ Number of children } & 20.87 & $0.01 * *$ \\
\hline 0 & $78(48.1)$ & $133(60.7)$ & & \\
\hline 1 & $43(26.5)$ & $68(31.1)$ & & \\
\hline$\geq 2$ & $41(25.3)$ & $18(8.2)$ & & \\
\hline \multicolumn{3}{|c|}{ Expected timing of next pregnancy (years) } & 11.83 & $0.01 * *$ \\
\hline$<2$ years & $54(33.3)$ & $106(48.4)$ & & \\
\hline$\geq 2$ years & $56(34.6)$ & $62(28.3)$ & & \\
\hline Does not want more children & $36(22.2)$ & $27(12.3)$ & & \\
\hline
\end{tabular}


Table 3 Associations between demographic/reproductive factors and an intention to use LARCs within women with unintended pregnancy during the post-abortion period $(n=381)$ (Continued)

\begin{tabular}{llll}
\hline & $\begin{array}{l}\text { Intended to use LARC }(n=162) \\
f(\%)\end{array}$ & $\begin{array}{l}\text { No intended to use LARC }(n=219) \\
f(\%)\end{array}$ & $x^{2}$ \\
\hline Unknown & $16(9.9)$ & $24(11.0)$ & 0.01 \\
Aware of LARC & $144(88.9)$ & $194(88.6)$ & 0.93 \\
Yes & $18(11.1)$ & $25(11.4)$ & $\mathbf{7 . 6 3}$ \\
No & & $\mathbf{0 . 0 1 * *}$ \\
Previous LARC use & $21(13.0)$ & $11(5.0)$ & $208(95.0)$ \\
$\quad$ Yes & $141(87.0)$ &
\end{tabular}

*statistically significant by $x^{2}$ or $t$ tests with $p<0.05$

** statistically significant by $x^{2}$ or $t$ test with $p<0.01$

barrier was "worry about future fertility" (56.2\%). Additionally, participants reported the following: "fear of harm to health" (45.2\%), "concern about irregular bleeding or spotting" (44.6\%), "anxiety about IUD-related reproductive tract infections, movement, or loss of the device" (44.3\%), "lack of awareness about LARC", "fear of pain" (33.3\%), and "the process to insert or remove IUDs is tedious" (23.7\%; Table 5).

Table 4 Factors associated with an intention to use LARCs among women with unintended pregnancies seeking abortions ( $n=381)$

\begin{tabular}{|c|c|c|}
\hline \multirow{2}{*}{$\begin{array}{l}\text { Socio-demographic } \\
\text { characteristics }\end{array}$} & \multicolumn{2}{|c|}{ Intended to use LARC } \\
\hline & OR $(95 \%$ Cl) & $P$ \\
\hline \multicolumn{3}{|l|}{ Marital status } \\
\hline Married & $1.57(1.00-2.47)$ & 0.05 \\
\hline Single & 1 & \\
\hline \multicolumn{3}{|l|}{ Frequency of sexual activity } \\
\hline At least once per week & $3.34(1.03-10.78)$ & $0.04^{*}$ \\
\hline$<4$ times per month & $2.34(0.71-7.71)$ & 0.16 \\
\hline$<1$ time per month & 1 & \\
\hline \multicolumn{3}{|l|}{ Number of children } \\
\hline 0 & $0.29(0.13-0.68)$ & $0.01^{* *}$ \\
\hline 1 & $0.32(0.15-0.47)$ & $0.01^{* *}$ \\
\hline$\geq 2$ & 1 & \\
\hline \multicolumn{3}{|c|}{ Expected timing of next pregnancy (years) } \\
\hline$<2$ years & $0.97(0.43-2.12)$ & 0.94 \\
\hline$\geq 2$ years & $1.79(0.80-4.01)$ & 0.15 \\
\hline Does not want more children & $1.18(0.48-2.88)$ & 1.18 \\
\hline Unknown & 1 & \\
\hline \multicolumn{3}{|l|}{ Previous LARC use } \\
\hline Yes & $2.41(1.06-5.47)$ & $0.04^{*}$ \\
\hline No & 1 & \\
\hline
\end{tabular}

*statistically significant AOR with $p<0.05$

${ }^{* *}$ statistically significant AOR with $p<0.01$

\section{Discussion}

This study identified that only around two-fifths of Chinese women seeking abortion were interested in using a LARC. One-third intended to use IUDs, while only one in seven intended to use the implant method during the post-abortion period. These findings were consistent with a previous study conducted in China [26], which suggested that consultation may enhance access to LARCs. Wei and Liu [26] found that only 11.1 and $1.8 \%$ of women seeking abortion chose IUDs and contraceptive implants during the immediate post-abortion period prior to consultation with health professionals. After consultation, the intended use of IUDs and implants increased to 19.7 and $2.7 \%$, respectively.

The findings of the present study also indicated that women seeking abortion preferred IUDs to contraceptive implants. The one-child policy was introduced to control population in mainland China in 1979 [27]; however, since 2016, women in mainland China have been allowed to give birth to two children. During the period in which the one-Child policy was enforced, immediate post-placental insertion of an IUD was practiced as part of the standard care package received by all women following the birth of their first child [28]. This may have led to a high general level of acceptance of IUDs in China, while implants were relatively less known or under-used [26, 29].

Frequency of intercourse, marital status, number of living children, previous LARC use and excepted timing of next pregnancy were all shown to be significant predictors of a woman's intention to use a LARC. In contemporary mainland China, having sex before marriage is widely accepted among unmarried Chinese women, and this cohort showed a high intercourse frequency, as well as a high rate of induced abortion [30]. Research has also shown that the rate of IUD use among unmarried women is low $(6304,7.42 \%)$ [31] and that the majority of these women use short-acting contraceptives after abortion instead of LARCs [12]. However, post-placental 
Table 5 Potential barriers among women who do not intend to use LARC during the post-abortion period $(n=219)$

\begin{tabular}{lll}
\hline Women's perceptions & $f(\%)$ & Rank by frequency \\
\hline Worry about future fertility & $123(56.2)$ & 1 \\
Fear of harm to health & $99(45.2)$ & 2 \\
Worried about irregular bleeding or spotting & $97(44.3)$ & 3 \\
Fear of complications such as pregnancy with IUDs, reproductive tract infections, movement, or loss from uterus & $91(41.6)$ & 4 \\
Lack of awareness about LARC & $79(36.1)$ & 5 \\
Fear of pain & $73(33.3)$ & 6 \\
Process to insert or remove IUDs is tedious ${ }^{\mathrm{a}}$ & $52(23.7)$ & 8 \\
Fear of the surgical process of insertion or removal & $51(23.3)$ & 7 \\
Might cause abnormal menstruation & $48(21.9)$ & 8 \\
Performance without hormones & $45(20.5)$ \\
Friends or relatives have had bad experiences with LARC & $26(11.9)$ & 10 \\
Worried about weight gain & $17(7.8)$ & 11 \\
Too expensive & $10(4.6)$ & 12 \\
Have not been in a long-term relationship & $9(4.1)$ & 13 \\
Partner opposed to it & $9(4.1)$ & 13 \\
Prevented by religion from using the method & $5(2.3)$
\end{tabular}

${ }^{a}$ For instance, if a Procreation Certificate is needed, then one must go to a health care provider to have the device inserted or removed

insertion of an IUD is usually recommended to married women by health professionals [32]. The use of LARCs during the immediate post-abortion period is not the standard form of care. This indicates that LARCs might be under-utilized among unmarried women who have a high frequency of intercourse, and it is therefore important to address the barriers to LARC usage among unmarried women with high intercourse frequency and to promote its use among this group in order to reduce the risk of unintended pregnancy and repeated induced abortion.

Furthermore, the present study found that women with no or only one child, or planned to have a child within two years were found to have less intent to use a LARC. A previous study by Fleming and Sokoloff also showed that women with more than one child were more likely to be interested in using IUDs than nulliparous women [22]. A study conducted by Anguzu and Tweheyo similarly indicated that women who had living children were 1.5 -times more likely to use a LARC compared to nulliparous women [20].

Previous LARC use was associated with whether participants were interested in LARC use in the post-abortion period. Evidence indicated that LARC users had a high degree of satisfaction with respect to this type of contraceptive [33]. Women who had previously used LARCs were 1.49-times more likely to intend to use a LARC [34].
Finally, this study indicated that barriers to the use of LARCs during the immediate post-abortion period included "worry about future fertility", "fear of harm to health", "may cause irregular bleeding", "fear of complications", and "lack of awareness about the methods". A previous study indicated that because women believed that LARC use would negatively impact upon their future fertility, they did not choose a LARC [35]. We similarly found that worry about future fertility was the main reason that women seeking abortion did not intend to use a LARC in the immediate post-abortion period. It is obvious that worries about the risk and side effects of LARCs was one of the main reasons preventing women from using LARCs. A study that surveyed women aged 16 to 25 years showed that factors influencing contraceptive technology choices included "familiarity with the methods", "whether or not the method contained hormones", "likely effect on periods", and "other side effects" [36]. A population of women who desired sterilization also had concerns about the side effects of LARCs [21].

Another barrier was a lack of awareness with regards to these methods. An internet-based study of $1982 \mathrm{fe}$ male undergraduates at a large mid-western university in the United States found that lack of education about LARCs was the primary reason participants rejected this method [37]. Whitaker et al. [23] found that women aged 14-24 were likely to have positive attitudes around 
IUD methods after undergoing a three-minute educational intervention, suggesting that such interventions may improve positive attitudes towards LARC use among women seeking abortions [9]. There remain many myths regarding the use of LARCs, particularly regarding its potential effect on future fertility, which may prevent women of reproductive age using it to avoid unwanted pregnancy [38]. In order to help women to make informed decisions, health care professionals should pay significant attention to providing women with information relating to LARCs, especially with regards to alleviating the barriers.

Our study has some limitations which should be taken into consideration. Firstly, this investigation was conducted in only one hospital and most participants were employed women of Han ancestry. These findings may not therefore be representative of other settings or apply to those who are not of Han ancestry or are unemployed. In addition, this study relied upon a questionnaire that relied upon self-reporting by the respondents. Thus, there was the potential for recall bias in these data. Finally, adding qualitative study questions could provide additional insights into these findings in future research.

\section{Conclusions}

This study has significant clinical utility for health care professionals working with Chinese women seeking abortion. To identify women seeking abortion who intend not to use LARCs, health care professionals should asses their marital status, frequency of sexual activity, number of children, planned timing of the next pregnancy, and previous LARC use.

Impaired future fertility, being harmful to health, irregular bleeding risk of IUD failure and lack of awareness with regards to LARCs were the main barriers to LARC use. It is important to promote the use of LARCs among unmarried Chinese women; particularly during the post-abortion period to reduce the risk of unintended pregnancy and repeated induced abortion. Health care professionals could develop strategies to enhance women's intentions to use LARCs, such as providing information to alleviate the barriers to LARC use.

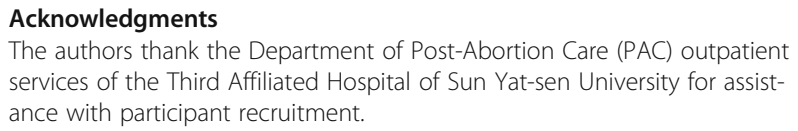

Ethic approval and consent to participate

Ethical approval was provided by the Medical Ethics Committee of Sun Yat-sen University.

\section{Funding}

This study did not receive any specific grant from funding agencies in the public, commercial, or not-for-profit sectors.

\section{Availability of data and materials}

The datasets used and/or analyzed during the current study are available from the corresponding author on reasonable request.

\section{Authors' contributions}

LZ conceptualized and designed the article, implemented result analysis and explanation, and was a major contributor in writing the manuscript. GL was responsible for quality control and reviewing the articles, critically revised all manuscript drafts, and generally managed the article. RA critically revised all manuscript drafts. ZJ analyzed and interpreted patient data. All authors read and approved the final manuscript.

\section{Competing interests}

The authors declare that they have no competing interests.

\section{Publisher's Note}

Springer Nature remains neutral with regard to jurisdictional claims in published maps and institutional affiliations.

\section{Author details}

${ }^{1}$ Nursing Department, Guizhou Provincial People's Hospital, Guiyang, China. ${ }^{2}$ School of Nursing, Sun Yat-sen University, 74\#, Zhongshan Road II, Guangzhou 510089, China. ${ }^{3}$ School of Public Health, Makerere University, Kampala city, Uganda.

Received: 15 October 2017 Accepted: 16 May 2018 Published online: 24 May 2018

\section{References}

1. Trussell J, Henry N, Hassan F, Prezioso A, Law A, Filonenko A. Burden of unintended pregnancy in the United States: potential savings with increased use of long-acting reversible contraception. Contraception. 2012; https://doi.org/10.1016/j.contraception.2012.07.016.

2. National Health And Family Commission. China health and family planning statistical yearbook, vol. 2015. BeiJing: China Union Medical University Press; 2015. p. 225-6.

3. Guo P, Liu Y, Tang F, Yang Y, Li P, Wang W. Analysis of current status of artificial abortion of 2956 cases and the evaluation of the effect of postabortion care in female reproductive health. Chin Gen Prac. 2016; https:// doi.org/10.3969/j.issn.1007-9572.2016.24.023. [In Chinese]

4. Wang $Y$, Yang Q. Changes in the high-risk factors of induced abortion in 2003 and 2013. J Chin Med Univ. 2015; https://doi.org/10.3969/j.issn.02584646.2015.11.018. [In Chinese]

5. Kolman KB, Hadley SK, Jordahliafrato MA. Long-acting reversible contraception: who, what, when, and how. J Fam Pract. 2015:64:479-84.

6. Lotke PS. Increasing use of long-acting reversible contraception to decrease unplanned pregnancy. Obstet Gynecol Clin N Am. 2015; https://doi.org/10. 1016/j.ogc.2015.07.008

7. Trussell J, Hassan F, Lowin J, Law A, Filonenko A. Achieving cost-neutrality with long-acting reversible contraceptive methods. Contraception. 2015; https://doi.org/10.1016/j.contraception.2014.08.011.

8. ACOG Practice Bulletin No. 121. Long-acting reversible contraception: implants and intrauterine devices. Obstet Gynecol. 2011; https://doi.org/10. 1097/AOG.0b013e318227f05e.

9. Rose SB, Lawton BA. Impact of long-acting reversible contraception on return for repeat abortion. Am J Obstet Gynecol. 2012; https://doi.org/10. 1016/j.ajog.2011.06.102.

10. Kilander H, Alehagen S, Svedlund L, Westlund K, Thor J, Brynhildsen J. Likelihood of repeat abortion in a Swedish cohort according to the choice of post-abortion contraception: a longitudinal study. Acta Obstet Gynecol Scand. 2016; https://doi.org/10.1111/aogs.12874.

11. Zhong Y, Huang Z. Analysis and following-up study of 1450 cases of women who received post-abortion care. Reprod Contracept. 2014; https:// doi.org/10.7669/j.issn.0253-357X.2014.04.0334. [In Chinese].

12. Wu X. Current situation analysis of contraception after abortion due to unintended pregnancy in unmarried women in Enping City[J]. China Modern Med. 2017;7:158-60. [In Chinese]

13. Guangzhou Bureau Of Statistics: The population scale and population distribution of Guangzhou in 2015. 2016. http://www.gzstats.gov.cn/tjgb/ qtgb/201611/t20161108_24979.html. Accessed 12 Sept 2017. 
14. Guangzhou Bureau Of Statistics: Census assembly, the sixth census in Guangzhou. 2013. http://www.gzstats.gov.cn/pchb/dlcrkpc/. Accessed 12 Sept 2017.

15. Guangzhou Bureau Of Statistics: 2016 Guangzhou Statistical Yearbook,Number of Health Institutions. 2016. http://data.gzstats.gov.cn/ gzStat1/chaxun/njsj.jsp/. Accessed 12 September 2017.

16. Corbett MR, Turner KL. Essential elements of postabortion care: origins, evolution and future directions. Int Fam Plan Perspect. 2003; https://doi.org/ 10.1363/ifpp.29.106.03

17. Kish L. Sampling organizations and groups of sizes. Am Sociol Rev. 1965;30:564-72.

18. Song $X, M a Y, Z$ uo L, Xu Y, Ling L. Status and influencing factors of induced abortion among childbearing women with different household registration in Guangzhou. Chin J Fam. 2013; https://doi.org/10.3969/j.issn.1004-8189. 2013.11. [In Chinese]

19. Potter J, Rubin SE, Sherman P. Fear of intrauterine contraception among adolescents in new York City. Contraception. 2014; https://doi.org/10.1016/j. contraception.2014.01.011.

20. Anguzu $R$, Tweheyo $R$, Sekandi JN, Zalwango V, Muhumuza C, Tusiime S, et al. Knowledge and attitudes towards use of long acting reversible contraceptives among women of reproductive age in Lubaga division, Kampala district, Uganda. BMC Res Notes. 2014; https://doi.org/10.1186/ 1756-0500-7-153.

21. White K, Hopkins K, Potter JE, Grossman D. Knowledge and attitudes about long acting reversible contraception among Latina women who desire sterilization. Womens Health Issues. 2013; https://doi.org/10.1016/j.whi.2013.05.001.

22. Fleming KL, Sokoloff A, Raine TR. Attitudes and beliefs about the intrauterine device among teenagers and young women. Contraception. 2010; https://doi.org/10.1016/j.contraception.2010.02.020.

23. Whitaker AK, Johnson LM, Harwood B, Chiappetta L, Creinin MD, Gold MA Adolescent and young adult women's knowledge of and attitudes toward the intrauterine device. Contraception. 2009; https://doi.org/10.1016/j. contraception.2008.04.119.

24. Mekonnen $\mathrm{G}$, Enquselassie $\mathrm{F}$, Tesfaye $\mathrm{G}$, et al. Prevalence and factors affecting use of long acting and permanent contraceptive methods in Jinka town, Southern Ethiopia: a cross sectional study[J]. Pan Afr Med J. 2014; https://doi.org/10.11604/pamj.2014.18.98.3421.

25. Burns B, Grindlay K, Dennis A. Women's awareness of, interest in, and experiences with long-acting reversible and permanent contraception[J]. Women's Health Issues. 2015; https://doi.org/10.1016/j.whi.2014.12.006.

26. Wei Z, Liu H. Influence of informed choice on induced abortion. Reprod Contracept. 2009;29:264-8. [In Chinese]

27. Yang X, Gao LL, Ip WY, Sally Chan WC. Predictors of breastfeeding selfefficacy in the immediate postpartum period: a cross-sectional study[J]. Midwifery. 2016; https://doi.org/10.1016/j.midw.2016.07.011

28. Xu JX, Connell C, Chi IC. Immediate postpartum intrauterine device insertion-a report on the Chinese experience[J]. Adv Contracept. 1992;8(4):281-90.

29. Pan $Y$, Che $Y$, Zhu H, Shen J, Lu Z, Lu M. Intrauterine device utilization of married women of childbearing age in shanghai during 2004-2012. Reprod Contracept. 2015; https://doi.org/10.7669/j.issn.0253-357X.2015.04 0259. [In Chinese]

30. Xiao $Y$, Mao Z, Liu L, Yang $Y$, Zhu $H$. Analysis on reason of induced abortion of 569 unmarried female. Matern Child Health Care China. 2007; https://doi. org/10.3969/j.issn.1001-4411.2007.28.034. [In Chinese]

31. Zhao H. Current Status of Family Planning/Reproductive Health and Evaluation of Quality of Care among Internal Migrants in Three Chinese Large Cities. Shanghai: Fudan University; 2011. [Dissertation in Chinese]

32. Liu Y. Situation and trend of contraceptive use among reproductive aged women in China[J]. Chin J Fam Plann. 2014; https://doi.org/10.3969/j.issn. 1004-8189.2004.05.001.

33. Diedrich JT, Desai S, Zhao Q, Secura G, Madden T, Peipert JF. Association of short-term bleeding and cramping patterns with long-acting reversible contraceptive method satisfaction. Am J Obstet Gynecol. 2015; https://doi. org/10.1016/j.ajog.2014.07.025.

34. Dassah ET, Odoi AT, Owusuasubonteng G. Prevalence and factors predictive of long-acting reversible contraceptive use in a tertiary hospital in urban Ghana. Eur J Contracept Reprod Health Care. 2013; https://doi.org/10.3109/ 13625187.2013.790951.

35. Bracken J, Graham CA. Young women's attitudes towards, and experiences of, long-acting reversible contraceptives. Eur J Contracept Reprod Health Care. 2014; https://doi.org/10.3109/13625187.2014.917623.
36. Rose SB, Cooper AJ, Baker NK, Lawton B. Attitudes toward long-acting reversible contraception among young women seeking abortion. J Women's Health. 2011; https://doi.org/10.1089/jwh.2010.2658.

37. Hall KS, Ela E, Zochowski MK, Caldwell A, Moniz M, McAndrew L, et al. 'I don't know enough to feel comfortable using them': Women's knowledge of and perceived barriers to long-acting reversible contraceptives on a college campus. Contraception. 2016; https://doi.org/10.1016/j. contraception.2016.02.007.

38. Russo JA, Miller E, Gold MA. Myths and misconceptions about long-acting reversible contraception (LARC). J Adolesc Health. 2013; https://doi.org/10. 1016/j.jadohealth.2013.02.003

\section{Ready to submit your research? Choose BMC and benefit from:}

- fast, convenient online submission

- thorough peer review by experienced researchers in your field

- rapid publication on acceptance

- support for research data, including large and complex data types

- gold Open Access which fosters wider collaboration and increased citations

- maximum visibility for your research: over $100 \mathrm{M}$ website views per year

At BMC, research is always in progress.

Learn more biomedcentral.com/submissions 